\title{
Fault detection in the manufacturing process of form-wound coils by means of dissipation factor and hipot tests
}

\author{
M.G. Melero, M.F. Cabanas, C.H. Rojas, J. Norniella, F. Pedrayes and J.M. Barrera \\ University of Oviedo \\ Electrical Engineering Dept. \\ Campus de Viesques - 33204 Gijón (Spain) \\ Fax:+34985 182453, e-mail: melero@uniovi.es,manes@uniovi.es, chrojas@uniovi.es, \\ jgnorniella@uniovi.es, pedrayesjoaquin@uniovi.es
}

\begin{abstract}
The resin rich process is quite commonly used in rewinding tasks of medium voltage rotating electric machines. This process involves the application of mica paper tapes, impregnated with epoxy resin, to the coils to be manufactured. These pre-impregnated tapes are then consolidated by confining coils in molds while applying heat and pressure. During the manufacturing processes defects may appear in the wrapping of the insulating tape. These defects can be caused by bad quality of the tape, irregularities and incorrect control of pressure or temperature during the pressing and curing process and errors during the manual wrapping process. As it will be analysed in this paper, these defects might not be detected by the usual electric tests applied in the quality control processes. As a consequence, the coil's useful life, and its resistance to the different stresses applied to the machine during operation, would be reduced. Then, this paper presents a preliminary study carried out on form-wound coils with mica-epoxy insulation. Measurements obtained from electric tests, as dissipation factor or hipot tests, reveals that they are not able to detect some defects in the coil insulation.
\end{abstract}

\section{Key words}

Form-wound coil, insulation failure, dissipation factor test, hipot test.

\section{Introduction}

High voltage electric motors and generators are essential components of the electrical power systems since their perfect operation determines the quality of power supply. Moreover, faults affecting these machines are usually serious for the electrical facility and the production process in which they are involved.

Insulation faults are the most critical breakdown on electrical rotating machines because of the following reasons:

1) Together with bearing faults they are the most frequent failure [1, 2]. In fact, depending on the industrial sector where the machine is used, insulation faults may reach up to the $50 \%$ of the total number of breakdowns, [3].

2) Time required for the purchase of materials needed for the manufacturing of coils, their building and the installation in the machine may be several weeks long. For this reason, insulation faults put the machines out of service for long periods of time.

3) The long time needed for repair and the high cost of materials dramatically increase the expenses involved in this type of breakdown. In fact, stator insulation faults are the most expensive failures in electrical rotating machinery.

4) Independently of the cause of failure, and even if it begins with an interturn short-circuit, final result is always a phase to phase or phase to ground insulation fault that produces the machine stop $[4,5]$. Fault currents generated during the insulation fault have a negative influence on the power system since they produce heating, voltage sags, electrodynamic stresses, etc.

The above reasons make the prevention of insulation faults on the stator windings of rotating machinery an important goal to improve the quality of electrical power systems. To achieve such an improvement two different tasks must be carried out: on the one hand, periodical revision of the insulation systems must be performed. On the other hand, a precise and reliable quality control must be applied to the coils manufacturing process in order to prevent manufacturing defects that could lead to a latter insulation fault.

Periodical testing of insulation systems is usually carried out into the scope of the plant programmed maintenance. The testing procedure consists of the application of electrical tests to estimate the actual condition of stator insulation, [1]. If the tests results indicate a poor condition of the insulation system its reparation can be programmed avoiding the machine breakdown during service. 
A quality control must be applied to the coils manufacturing process in order to prevent manufacturing defects that could lead to a latter insulation fault. The manufacturing process involves hand-made tasks and in this way different kinds of asymmetries, irregularities or defects can appear as a consequence of incorrect wrapping of the different layers of insulating tape. Moreover, other factors as differences in the quality of the tape, excess or defect in pressure, incorrect pressing temperature, etc, contribute to generate voids into the groundwall of the coil and a lack of compaction of the insulation reducing its useful life or even preventing its normal operation. For these reasons, a precise and reliable quality control is necessary in order to prevent manufacturing defects. This quality control is carried out by means of tests similar to those ones used in periodical maintenance [1]. This paper presents a study about the effectiveness of some of these test procedures in the detection of manufacturing defects.

\section{Form-wound coils}

Medium voltage rotating machines have stator windings made up of form-wound coils (Fig. 1). The main property of this type of winding is that the position of adjacent turns is controlled to prevent turns with large voltage differences from being close to one another. This ensures that in large motors adjacent turns have only a few volts across the insulation. Thus, thickness of turn insulation can be reduced. Each form-wound coil has two or three different insulation components, but the main insulation is the groundwall, which must be capable of operating at the rated voltage of the motor. The turn insulation separates the different copper turns from one another. Finally, taking into account that every coil turn is usually made of two or more strands, strand insulation is also applied in order to insulate copper strands from one another.

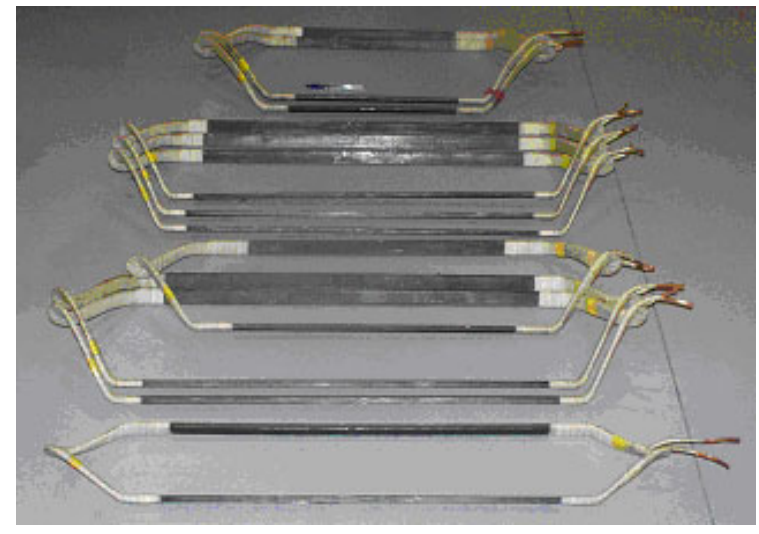

Fig. 1. Different types of form-wound coils

a) Modern groundwall insulation systems are composed of thermosetting insulation, which is mica paper impreg-nated with polyester or, generally, epoxy resin acting as a bonding material. One of the methods used in rewinding tasks to make the epoxy mica groundwall is the so called resin rich process. This process involves the application of mica paper tapes that have been impregnated with epoxy resin. The method preferred by most repair shops to consolidate the preimpregnated tapes is based on a pressed system. This system consists of building the coils by confining them into molds and directly apply on them heat and pressure. (Fig. 2). This system provides coils insulation with a good combination of electrical, mechanical, thermal and environmental properties.

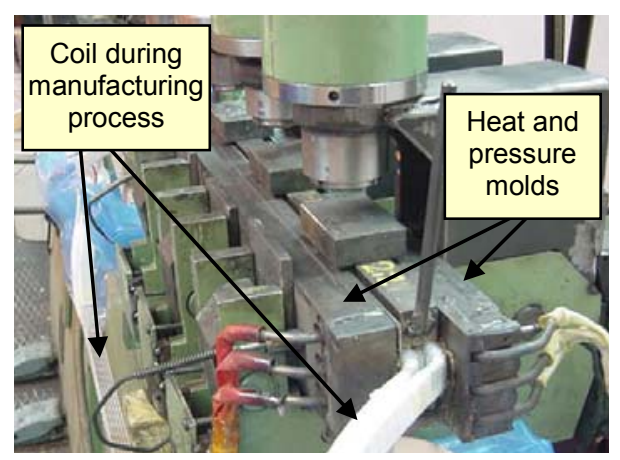

Fig. 2. Coil during manufacturing process in press

Asymmetries, irregularities or defects may appear in the coils during any of the above processes. In order to detect these manufacturing problems, several tests are available in the industry [1], but two of them are especially used to detect flaws in the groundwall insulation: dissipation factor test (also known as power factor test) and hipot test. These two tests will be used in the present study to check their ability to detect failures in the manufacturing process of form-wound coils.

For this purpose, twelve coils were manufactured in two different ways, in order to obtain a group of four healthy coils and a group of eight faulty coils. In both cases, coils were built according to the specifications of a $5 \mathrm{kV}, 5$ MW motor. Resin rich manufacturing process was used as explained above. The difference between healthy and faulty coils is due to the manufacturing process that, in the latter case, is intentionally done with a faulty impregnated tape (not enough resin) which causes a lack of compaction in the groundwall insulation.

\section{Dissipation factor and hipot tests}

\section{A. Dissipation factor test.}

Dissipation factor tests are dielectric tests carried out by applying $\mathrm{AC}$ voltage to all or part of a winding during a suitable outage. They have proven themselves over many years to be valuable tools to evaluate both the manufacturing quality of a coil and the condition they are in while operating. This type of test is sensitive to the internal condition of the groundwall and is particularly useful for high voltage motor windings. However, the usefulness of a single measurement of the power factor on a complete winding is limited. To obtain relevant information about the insulation tendency results of testing coils or groups of coils over a period of years are needed [6].

Dissipation factor test is based on the fact that dielectric losses exist in any insulation material. Ideally the 
insulation will act as a pure capacitor, but in practice the groundwall insulation will dissipate some energy. At low voltage, the cause of this dissipation is mainly the movement of polar molecules under the AC electric field. At high voltages, the cause is completely different. In the groundwall of the coil insulation, there can be air-filled voids. When a sufficiently high voltage is applied to the insulation, partial discharges can occur in these voids; these are, in other words, small electrical discharges (partial discharges) that produce heat and light and that therefore cause a certain amount of energy consumption that increases the electrical losses in the winding. This process means that an increase in the dissipation factor is directly related to an increase in the voltage applied.

As can be seen, the real insulation can be modelled, as regards its electrical behaviour, as an ideal capacitor connected in series or in parallel to a resistance representing dielectric losses.

By using parallel circuit (Fig. 3), the value that the tan $\delta$ assumes is:

$$
\tan \partial=\frac{I_{R}}{I_{C}}
$$

$I_{R}$ and $I_{C}$ being the currents trough the resistor and the capacitance of the model respectively. The $\tan \delta$ value expressed in terms of impedances would be:

$$
\tan \partial=\frac{X}{R}=\frac{1}{\omega C R}
$$

In this equation, $X$ is parallel reactance, $R$ is parallel resistance, $C$ is parallel capacitance and $\omega$ is $2 \pi \mathrm{f}$.

The tan $\delta$ term is also known as the dielectric dissipation factor [7], as it reflects the importance its resistive component has on the actual capacitor. It is therefore a measurement of the electrical losses that occur in the insulation.
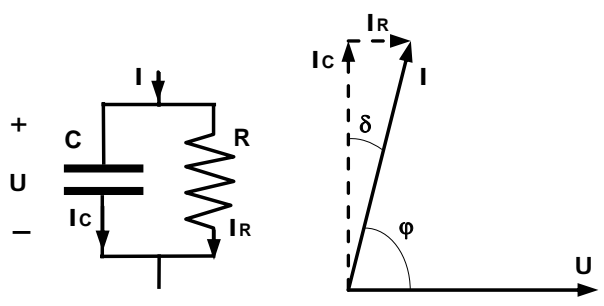

Fig. 3. Parallel circuit and vector diagram for dissipation factor calculation

This test is performed on individual coils to determine if they have been properly impregnated. If increasing AC voltage is applied to a coil and voids are present within the groundwall, then partial discharges will appear at some voltage. Consequently, a certain amount of energy consumption increases the electrical losses and the dissipation factor will also increase above the level measured at lower voltages. The greater the increase in the dissipation factor, the more the energy will be consumed by the partial discharge activity and therefore the higher the number or magnitude of the insulation defects. Then, the measurement of dissipation factor increment (tip-up) between low and high voltage is an indirect way of determining if partial discharges are occurring. This is the so called dissipation factor tip-up test.

\section{B. Hipot test.}

Using overvoltage tests - high potential or hipot tests with either AC or DC voltage provides information about the dielectric strength of the insulation system. Therefore, overvoltage testing gives an idea as to the capacity of the insulation system to withstand dielectric stresses. An overvoltage test consists of deliberately applying an AC or DC voltage that is higher than the rated voltage of the machine's winding. If the insulation withstands this voltage for set time period without there being exceptionally high current flow, it is supposed that it will also be able to withstand the rated voltage during working without being at risk.

Tests of this type are done when coils or machines have just been manufactured or when they are being used for the first time to test their acceptability. They are also often used on machines that are in service for maintenance purposes, or when maintenance checks are carried out on the windings to check for damage. Whatever the case, the test outcome is simply pass or fail and they provide some guarantee that the groundwall can safely withstand the electric stress that occurs at the machine's standard operating voltage.

The principle behind the hipot test is that weakened insulation will break down if it is subjected to a high enough voltage. Test voltage is selected so that good insulation will pass the test, whereas damaged insulation will break down during the test. In principle, an insulation that fails this kind of test can be expected to fail in a relatively short period of time if placed in service without first being subject to the hipot test. Experience shows that many weak points are discovered by the test, and that many in-service breakdowns can thus be avoided.

\section{Test procedures}

All coils manufactured for this study were built according to the specifications explained in point 2 and they were tested with dissipation factor tip-up and hipot tests as follows:

\section{A. Dissipation factor tip-up test procedure.}

The dissipation factor measurements were carried out with a Tettex Instruments automatic insulation power loss test system (Fig. 4). This system can measure capacitances with small losses $\left(\mathrm{I}_{\mathrm{R}}<<\mathrm{I}_{\mathrm{C}}\right.$ in Fig. 3), as it is the case of coils insulation. The measurement principle is explained below and is detailed in [8]. As shown in fig. 5, the purely capacitive signal trough the reference capacitor is taken and its polarity is inverted and fed into the branch of the coil under test. 


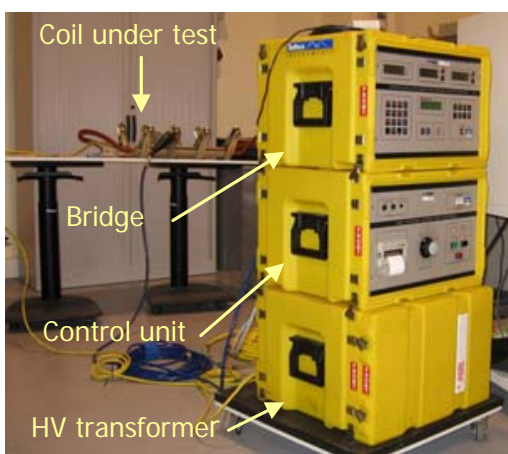

Fig. 4. Dissipation factor measurement system

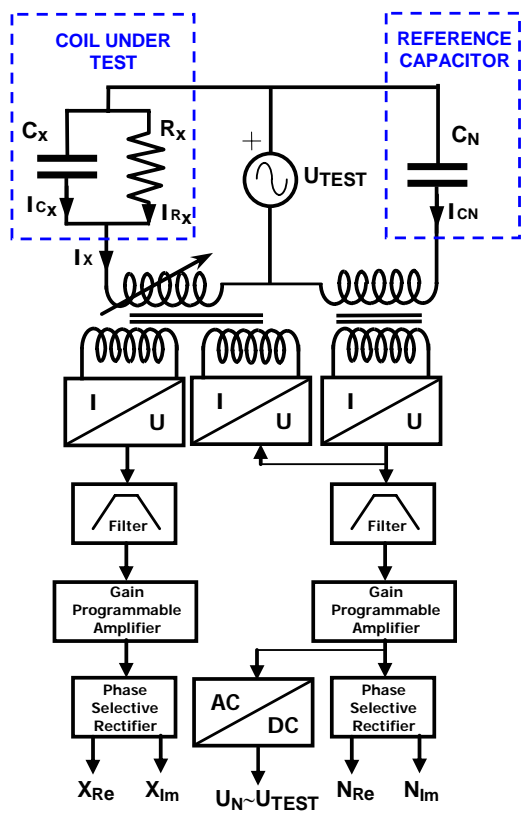

Fig. 5. Scheme of the system used in the tests for dissipation factor measurement

This process is done in such a way that the $I_{C X}$ component is compensated as fully as possible. The very small $\mathrm{I}_{\mathrm{RX}}$ component remains and can be amplified and measured with adequate resolution. Additionally, highly selective filters are used to isolate the $50 \mathrm{~Hz}$ component in the measurement signal.

The dissipation factor test was performed by increasing voltage from $0 \mathrm{~V}$ to $\mathrm{Un} \mathrm{kV}$ (Un being the rated phase-tophase voltage of the coil) in $0.2 \cdot$ Un steps $[9,10]$; i.e. 1 $\mathrm{kV}, 2 \mathrm{kV}, 3 \mathrm{kV}, 4 \mathrm{kV}$ and $5 \mathrm{kV}$. For each voltage, dissipation factor value is recorded and programmed to be averaged during 20 frequency cycles. From the recorded values, the parameters used for diagnosis were the following:

1) Value of the dissipation factor at $20 \%$ of rated voltage $\left(\operatorname{tg} \delta_{0.2}\right)$.

2) Half an increase in the dissipation factor between $20 \%$ and $60 \%$ of the rated voltage $\left(1 / 2\left(\operatorname{tg} \delta_{0.6}-\operatorname{tg} \delta_{0.2}\right)\right)$.

3) An increase in the dissipation factor each $20 \%$ of rated voltage $(\Delta \operatorname{tg} \delta)$.

4) The dissipation factor tip-up calculated between $100 \%$ and $25 \%$ of rated line-to-ground voltage. The tip-up is the difference between the two readings.
To select these parameters, the standards recommendations [10], the scientific literature results, $[1$, 7] and the criteria followed nowadays by users of machines with epoxy-mica insulating systems were applied. In the same way, acceptation levels were defined according to literature [1]. Values indicated by [10] were reduced by following the specifications commonly applied by users. Table I shows the maximum admissible values of every parameter.

TABLE I. - Diagnosis parameters and acceptance levels

\begin{tabular}{|c|c|c|c|c|}
\hline Parameter & $\operatorname{tg} \delta_{0.2}$ & $1 / 2\left(\operatorname{tg} \delta_{0.6}-\operatorname{tg} \delta_{0.2}\right)$ & $\Delta \operatorname{tg} \delta$ & tip-up \\
\hline Value & $300 \cdot 10^{-4}$ & $25 \cdot 10^{-4}$ & $30 \cdot 10^{-4}$ & $50 \cdot 10^{-4}$ \\
\hline
\end{tabular}

\section{B. Hipot test procedure.}

Hipot tests can be performed either with DC or AC voltage. For this study, AC version was selected because flaws that might cause puncture in the coil may escape detection with a DC test, but can be more easily detected with an $\mathrm{AC}$ test. This is due to the more uniform electric field distribution with $\mathrm{AC}$ voltage causing the same stress as that which occurs during normal operation.

Every coil was subjected to an AC hipot test after a dissipation factor test. Hipot test consisted of a quick voltage increase to their maximum test value keeping it on this status during 1 minute. After this period voltage was quickly decreased to 0 . Since this is a go no-go test, the only result after performing it is a coil without or with a puncture in the groundwall. The maximum test voltage was established according to the following expression:

$$
\mathrm{U}_{\mathrm{MAX}}=2 \cdot \mathrm{U}_{\mathrm{N}}+1
$$

Where $\mathrm{U}_{\mathrm{MAX}}$ stands by the maximum test voltage and $\mathrm{U}_{\mathrm{N}}$ the coil rated voltage, (both measured in $\mathrm{kV}$ ). This is a quite common acceptance level [1]. For this study, since the rated voltage is $5 \mathrm{kV}$, the test voltage is $11 \mathrm{kV}$. This voltage was obtained by means of the HV transformer belonging to the dissipation factor measurement system (Fig. 4).

\section{Test results}

Tables II and III show the results achieved in dissipation factor and hipot tests. From these data, values of the parameters selected for diagnosis were obtained (Tables IV and V) and analysed. To carry out the study the complete set of coils was split up into three groups:

1) A group of completely healthy coils (\#1 to \#4 in Tables II - V). This is the group G\# in Tables IV and $\mathrm{V}$. These are that showed a good behaviour during the tests.

2) A group of faulty coils. This is the group $B \#$ in Tables IV and V. This set of coils is formed by those that did not clearly pass the acceptance levels.

3) A group of pseudo-healthy coils. This is the group $\mathrm{P} \#$ in Tables IV and V. These are the rest of the faulty coils. Despite the fact that they were actually 
faulty coils due to the flawed tape used, they passed the acceptance levels during the tests.

TABLE II. - Dissipation factor values (x 10 $\left.0^{-4}\right)$

\begin{tabular}{|c|c|c|c|c|c|}
\hline \#COIL & $\operatorname{tg}_{\boldsymbol{0}_{\mathbf{2}}}$ & $\mathbf{t g}_{\mathbf{0 . 4}_{\mathbf{4}}}$ & $\mathbf{t g}_{\mathbf{0 . 6}}$ & $\mathbf{t g} \boldsymbol{\delta}_{\mathbf{0 . 8}}$ & $\mathbf{t g} \boldsymbol{\delta}_{\mathbf{1}}$ \\
\hline$\# 1$ & 70 & 70 & 71 & 77 & 86 \\
\hline$\# 2$ & 61 & 61 & 62 & 70 & 81 \\
\hline$\# 3$ & 60 & 61 & 61 & 67 & 80 \\
\hline$\# 4$ & 58 & 58 & 59 & 67 & 78 \\
\hline$\# 5$ & 71 & 72 & 73 & 86 & 103 \\
\hline$\# 6$ & 74 & 74 & 81 & 112 & 133 \\
\hline$\# 7$ & 70 & 71 & 86 & 129 & 148 \\
\hline$\# 8$ & 74 & 75 & 75 & 79 & 87 \\
\hline$\# 9$ & 65 & 66 & 72 & 89 & 140 \\
\hline$\# 10$ & 57 & 58 & 60 & 71 & 84 \\
\hline$\# 11$ & 60 & 60 & 61 & 67 & 78 \\
\hline$\# 12$ & 57 & 58 & 60 & 75 & 106 \\
\hline
\end{tabular}

TABLE III. - Hipot test results

\begin{tabular}{|c|c|c|c|c|c|c|c|c|c|c|c|c|}
\cline { 2 - 10 } \multicolumn{1}{c|}{} & \multicolumn{10}{c|}{ \#COIL } \\
\cline { 2 - 11 } \multicolumn{1}{c|}{} & $\# 1$ & $\# 2$ & $\# 3$ & $\# 4$ & $\# 5$ & $\# 6$ & $\# 7$ & $\# 8$ & $\# 9$ & $\# 10$ & $\# 11$ & $\# 12$ \\
\hline Passed & $\mathrm{X}$ & $\mathrm{X}$ & $\mathrm{X}$ & $\mathrm{X}$ & $\mathrm{X}$ & $\mathrm{X}$ & & $\mathrm{X}$ & & $\mathrm{X}$ & $\mathrm{X}$ & $\mathrm{X}$ \\
\hline Failed & & & & & & & $\mathrm{X}$ & & $\mathrm{X}$ & & & \\
\hline
\end{tabular}

Coils from group G\#, as they were supposed, showed a good behaviour in the tests. The measured dissipation factor values and the parameters calculated from them are lower than those established as maximum admissible levels (Table I). In Fig. 6, dissipation factor data are plotted. It can be seen that all coils have a quite flat curve showing low dissipation factor increments (Fig. 7). Moreover, all curves are very close one to another, so not only all coils have been well impregnated, but also they have a homogeneous quality. All these coils passed the hipot test as it is shown in Table III.

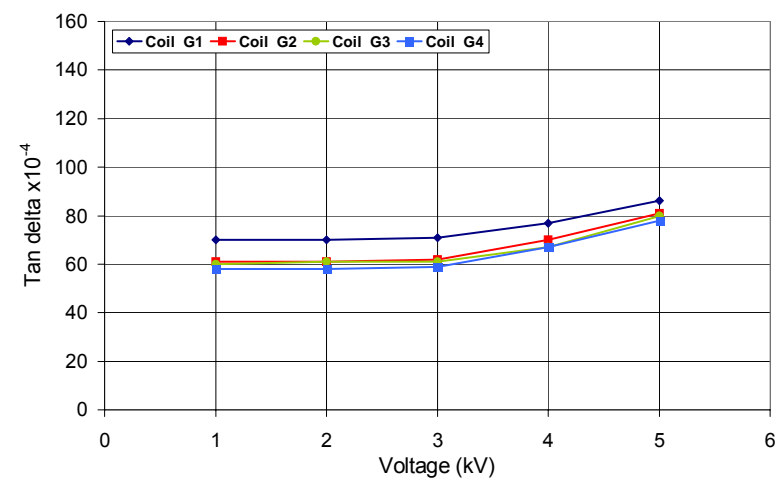

Fig. 6. Dissipation factor $(\tan \delta)$ tests performed on coils from group $\mathrm{G}$.

Coils from group B\# were built with flawed tape, so, as it was expected, they did not clearly pass the acceptance levels. For these coils, the dissipation factor values in the final voltage steps (Fig. 8), as well as the increments of this factor when voltage was greater than $3 \mathrm{kV}$ (Fig. 9), were large enough to consider the presence of serious defects in the insulation system of the coils. In fact, the values of the dissipation factor rise (in bold letters in Table IV) were over the maximum admissible levels. Moreover, the curves showed scattering between them, so not only all coils had been wrongly impregnated, but also they have different features. Despite this, only two of these coils did not pass the hipot test. Nevertheless, all of them would be rejected for a machine rewinding or manufacturing.

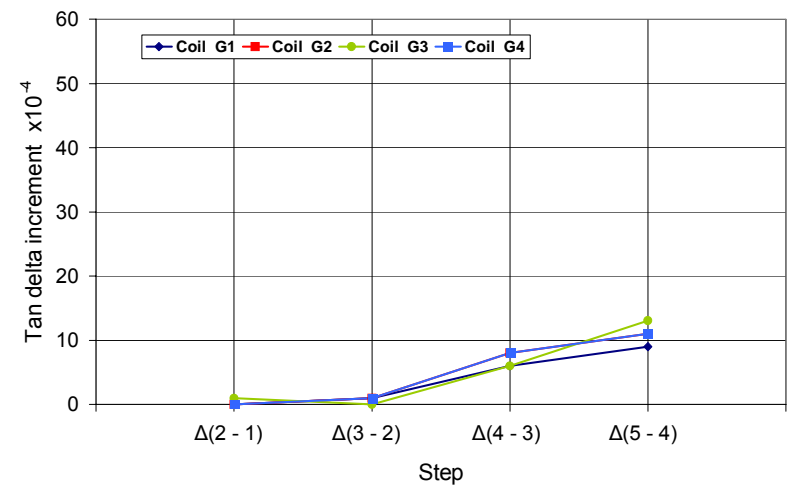

Fig. 7. Dissipation factor increments between two consecutive testing voltages. Coils from group $\mathrm{G}$.

TABLE IV. - Dissipation factor increments (x 10 $\left.0^{-4}\right)$ between two consecutive steps

\begin{tabular}{|c|c|c|c|c|c|}
\hline \multicolumn{2}{|c|}{ COIL } & $\begin{array}{c}\Delta \operatorname{tg} \delta \\
\operatorname{tg} \delta_{\mathbf{0 . 4}}-\operatorname{tg} \delta_{\mathbf{0 . 2}}\end{array}$ & $\begin{array}{c}\Delta \operatorname{tg} \delta \\
\operatorname{tg} \delta_{\mathbf{0 . 6}}-\operatorname{tg} \delta_{\mathbf{0 . 4}}\end{array}$ & $\begin{array}{c}\Delta \operatorname{tg} \delta \\
\operatorname{tg} \delta_{\mathbf{0 . 8}}-\operatorname{tg} \delta_{\mathbf{0 .}}\end{array}$ & $\begin{array}{c}\Delta \operatorname{tg} \delta \\
\operatorname{tg} \delta_{\mathbf{1}} \text {-tg } \boldsymbol{\delta}_{\mathbf{0 . 8}}\end{array}$ \\
\hline$\# 6$ & $\mathrm{~B} 1$ & 0 & 7 & 31 & 21 \\
\hline$\# 7$ & $\mathrm{~B} 2$ & 1 & 15 & $\mathbf{4 3}$ & 19 \\
\hline$\# 9$ & $\mathrm{~B} 3$ & 1 & 6 & 17 & $\mathbf{5 1}$ \\
\hline$\# 12$ & $\mathrm{~B} 4$ & 1 & 2 & 15 & $\mathbf{3 1}$ \\
\hline$\# 1$ & $\mathrm{G} 1$ & 0 & 1 & 6 & 9 \\
\hline$\# 2$ & $\mathrm{G} 2$ & 0 & 1 & 8 & 11 \\
\hline$\# 3$ & $\mathrm{G} 3$ & 1 & 0 & 6 & 13 \\
\hline$\# 4$ & $\mathrm{G} 4$ & 0 & 1 & 8 & 11 \\
\hline$\# 5$ & $\mathrm{P} 1$ & 1 & 1 & 13 & 17 \\
\hline$\# 8$ & $\mathrm{P} 2$ & 1 & 0 & 4 & 8 \\
\hline$\# 10$ & $\mathrm{P} 3$ & 1 & 2 & 11 & 13 \\
\hline$\# 11$ & $\mathrm{P} 4$ & 0 & 1 & 6 & 11 \\
\hline
\end{tabular}

TABLE V. - Diagnosis parameters from dissipation factor values $\left(\times 10^{-4}\right)$ and hipot test results

\begin{tabular}{|c|c|c|c|c|}
\hline \multicolumn{2}{|c|}{ COIL } & tg $\boldsymbol{\delta}_{\mathbf{0 . 2}}$ & $\mathbf{1} / \mathbf{2}\left(\mathbf{t g} \boldsymbol{\delta}_{\mathbf{0 . 6}}\right.$-tg $\left.\boldsymbol{\delta}_{\mathbf{0 . 2}}\right)$ & Tip-up \\
\hline$\# 6$ & B1 & 74 & 3.5 & 7 \\
\hline$\# 7$ & B2 & 70 & 8.0 & 16 \\
\hline$\# 9$ & B3 & 65 & 3.5 & 7 \\
\hline$\# 12$ & B4 & 57 & 1.5 & 3 \\
\hline$\# 1$ & G1 & 70 & 0.5 & 1 \\
\hline$\# 2$ & G2 & 61 & 0.5 & 1 \\
\hline$\# 3$ & G3 & 60 & 0.5 & 1 \\
\hline$\# 4$ & G4 & 58 & 0.5 & 1 \\
\hline$\# 5$ & P1 & 71 & 1.0 & 2 \\
\hline$\# 8$ & P2 & 74 & 0.5 & 1 \\
\hline$\# 10$ & P3 & 57 & 1.5 & 3 \\
\hline$\# 11$ & P4 & 60 & 0.5 & 1 \\
\hline
\end{tabular}

The group of faulty coils not included in group B\# are the pseudo-healthy coils and they were included in group P\#. They are called pseudo-healthy coils because they showed dissipation factor values in the final voltage steps, as well as increments of this factor, that were under the maximum admissible levels and thus not large enough to evaluate the coils as faulty. Despite this fact they were made with the same flawed tape used for the bad coils from group B\#. 
Regarding the dissipation factor vs. voltage curves (Fig. 10 and 11), their appearance is relatively flat and the obtained values are quite close one another. This behaviour is not as strong as it was in coils from group

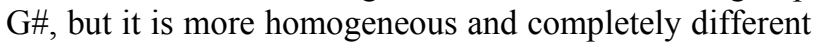
than the one obtained for coils from group $\mathrm{B} \#$. Nevertheless, all the coils successfully passed the hipot tests. For this reason, the pseudo-healthy behaviour of these coils would make possible that if they were intended for rewinding a machine, they would be used without any restriction. In fact, all the electrical tests did not really revealed the actual conditions of the insulating system in this set of coils.

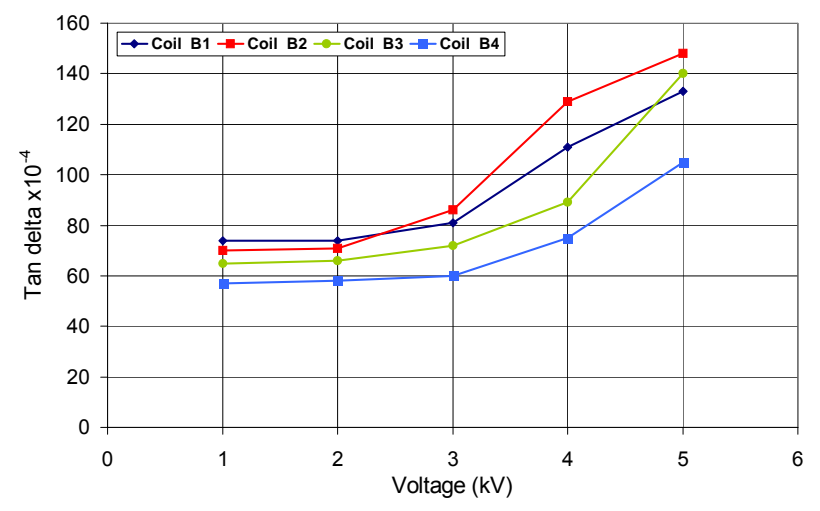

Fig. 8. Dissipation factor $(\tan \delta)$ tests performed on coils from group B.

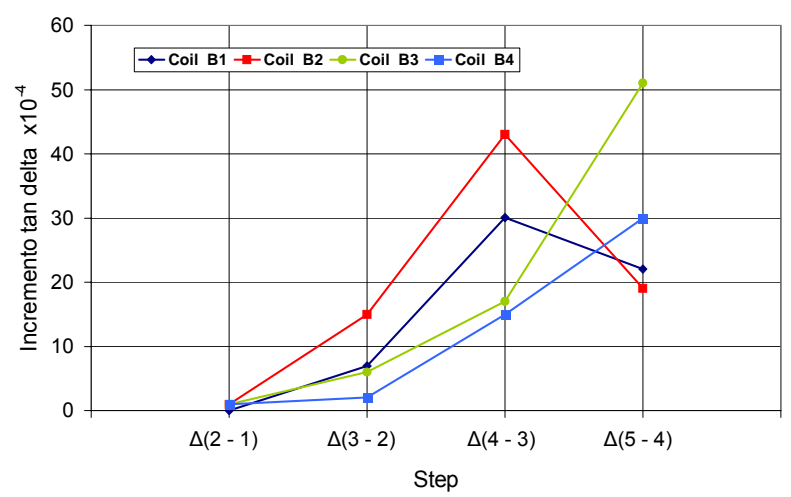

Fig. 9. Dissipation factor increments between two consecutive testing voltages. Coils from group B.

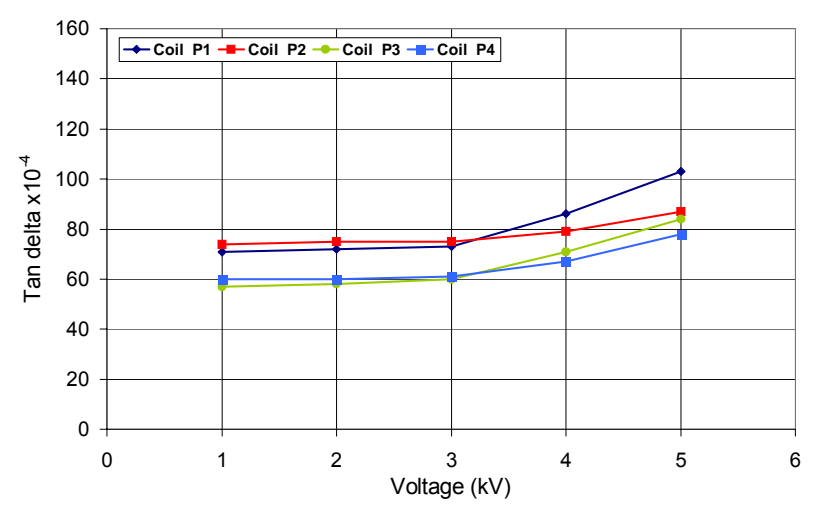

Fig. 10. Dissipation factor ( $\tan \delta$ ) tests performed on coils from group $\mathrm{P}$.

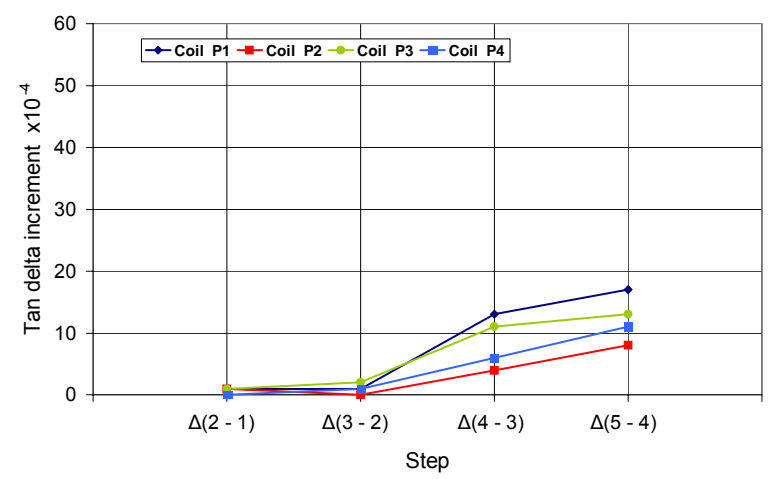

Fig. 11. Dissipation factor increments between two consecutive testing voltages. Coils from group P .

Several reasons exist for the wrong classification of these coils as healthy during the tests. In first place, the parameters and criteria used in diagnosis may be not sensitive enough to detect the faults applied to the taping of the insulating wall of the coils. This lack of sensitivity can be explained as follows:

From all the set of selected variables, only dissipation factor increase in the last voltage steps barely allows the identification of 4 faulty coils (coils belonging to group B\#). Even for these 4 coils the rest of parameters did not surpassed the maximum admissible levels.

Some of the variables used in the study and their maximum values are obtained from the standards [10]. This is the only reference that establishes acceptation levels for a set of manufactured coils. These levels are valid for machines whose rated voltage is higher or equal to $5 \mathrm{kV}$ and whose rated power is equal or higher than 5 MW. Coils used in the study belong to a $5 \mathrm{kV}-5 \mathrm{MW}$ machine; therefore, they are in the lowest limit indicated in the standard for its application. The fact that coils are in the limit of application of the standard may suggest a lower sensitivity for fault detection. In fact, it must be taken into account that from all the analysed coils only those that did not pass the criterion applied by users of electrical machines (which reduces the limit values defined by the standard) were classified as faulty. If this diagnosis criterion had not been applied no faulty coils had been detected during the experimental tests.

In second place, coils defined as pseudo-healthy would have been diagnosed as healthy since dissipation factor test is not sensitive enough to taping flaws as the used in the manufacturing of these set of coils. The insensitivity of dissipation factor tests to the above type of defect can be easily understood if some peculiarities of this test are taken into account: although in [1] this testing method is defined as applicable to coils of any rated voltage, it is also affirmed that it usually applies to machines with a voltage rating of $6 \mathrm{kV}$ and higher. Moreover, it is well known that dissipation factor test measures the global partial discharge activity as an average of the total discharges present in the insulation groundwall. Therefore, as presented in [11], the detection of certain kind of defects in this region of the insulating system may be really difficult if only this test is applied. Taking into account that rated voltage of the studied coils is 5 $\mathrm{kV}$, it is reasonable thinking that partial discharge 
activity at $5 \mathrm{kV}$ with the applied taping defect may be not high enough to be detected as a change in the dissipation factor measured in the insulation.

\section{Conclusions}

The results of the present study point out the difficulty for the detection of faults derived from the use of flawed tape in the wrapping process of form-wound coils with epoxy-mica insulation. In this sense, two groups of coils, with and without flawed tape, were manufactured and analysed by means of dissipation factor and hipot tests. The healthy coils, as they were supposed, showed a good behaviour during both tests. The values obtained of dissipation factor agreed with the commonly admitted criteria to accept a coil correctly manufactured.

The faulty coils showed a different behaviour during the tests and it was observed that another two groups of coils could be formed from them. The first one composed by coils which did not pass the acceptation criteria. Thus, as it was expected, these coils would be rejected for a reliable rewinding. The other group of faulty coils was formed by the coils whose test results were positive for dissipation factor and hipot tests. If these coils were intended for rewinding, they would be used without any restriction, since the tests did not reveal the actual condition of their insulating systems.

In this way, the insensitivity of dissipation factor and diagnosis parameters commonly used for the detection of faults in the groundwall of epoxy-mica insulating system has been demonstrated. In fact, in the analysed case ( 5 $\mathrm{kV}, 5 \mathrm{MW}$ coils) variables and admissible values defined by the standards are not capable of correctly classifying the coils as healthy or faulty. This erroneous diagnosis is probably caused by the combination of dissipation factor tests insensitivity to taping flaws with the rated voltage and power of the studied coils that locate them in the lowest applicable limit defined by the standards.

For this reason the need of developing new diagnosis variables, limits for their values and or tests to correctly classify pseudo-healthy coils is clearly demonstrated. In this way, the possibility of rewinding or manufacturing a machine with coils that would reduce its useful life and, as a consequence, would limit its continuity in service would be drastically reduced.

\section{References}

[1] Greg C. Stone, Edward A. Boulter, Ian Culbert, Hussein Dhirani, Electrical Insulation for Rotating Machines, Wiley-IEEE Press, USA 2004. ISBN 0471-44506-1.

[2] P. F. Albrecht, J. C. Appiarius, R. M. McCoy, E. L. Owen, and D. K. Sharma, "Assessment of the Reliability of Motors in Utility ApplicationsUpdated", IEEE Transactions on Energy Conversion Vol EC-1, No 1, March. 1986.

[3] R. Fournié; Les isolants en électrotechnique. Essais. Mécanismes de dégradation. Applications industrielles, Editions Eyrolles, Paris 1990. ISBN 03994198.

[4] O. M. Nassar, "The use of partial discharge and impulse voltage testing in the evaluation of interturn insulation failures of large ac motors", IEEE Transactions on Energy Conversion, Vol EC2, No 4 Dec. 1994.

[5] A. H. Bonnet, G. Soukoup, "Cause and analysis of stator and rotor failures in three phase squirrel-cage induction motors", IEEE Transactions on Industry Applications, vol. 28, n 4, July/August 1998

[6] M. F. Cabanas, M. G. Melero, G. A. Orcajo, J. M. Cano, J. Solares, Maintenance and Diagnostic Techniques for Rotating Electric Machinery - ABB - Marcombo, Boixareu Editores, Barcelona 1999. ISBN 84-267-1222-3

[7] IEEE Std 286-2000, "Recommended practice for measurement of power-factor tip-up of rotating machinery stator coil insulation"

[8] K. Fischer, "Dielectric measurement of highvoltage apparatus in the interference field of a substation", Tettex Instruments. Information note 26.

[9] IEC 60894-1987, "Guide for a test procedure for the measurement of loss tangent of coils and bars for machine windings"

[10] EN 50209-1998, "Test of insulation of bars and coils of high-voltage machines"

[11] S. Zamora, M. C. Caminero, M. G. Melero, M. F. Cabanas, A. Kortajarena, C. H. Rojas, G. A. Orcajo, "Diagnosis of failures in epoxy-mica insulating systems by means of partial discharges analysis and finite element models", in Proc. SDEMPED 2003, IEEE International Symposium on Diagnostics for Electric Machines, Power Electronics and Drives, Atlanta, GA, USA , 24-26 August 2003. 